\section{Disease should be targeted from all angles}

Sir - In his review ${ }^{1}$ of my book, Cancer: The Evolutionary Legacy, Leo Kinlen is unpersuaded that an evolutionary perspective on cancer causation is helpful. As an epidemiologist, Kinlen is more than entitled to hold contrary views to me. Scientists of differing specialties often have quite different perspectives on causation ${ }^{2}$. They each know what they mean, but a broader audience may be perplexed by limited horizons. That aside, Kinlen's critique raises substantive issues that merit further comment or debate.

On the contentious issue of causal mechanisms in breast and prostate cancer, Kinlen has, unfortunately, misconstrued my views. He says that I propose that environmental chemicals must (my emphasis) make a significant contribution to the cause of breast cancer and that sex is a likely cause of prostate cancer. On the contrary, on breast cancer I argue that the theory that environmental chemicals are an important cause of breast cancer has virtually no epidemiological support. I do say, however, that since unequivocal negation of the hypothesis is very difficult, it cannot be completely excluded. On prostate cancer, I state that I do not know the cause and that the idea suggested, though plausible, is "highly speculative".

On the challenge of cancer control, Kinlen reminds us that epidemiological insight into cancer causation and effective prevention is sometimes possible without any detailed knowledge of biological mechanisms, well-known examples being cigarette smoking and lung cancer, and melanoma and sun exposure. By the same token, childhood leukaemia was curable before we knew much about the biology of that disease. These epidemiological and clinical successes are laudable, but they also bring into sharp focus our past limitations and failures. Would cigarette manufacturers have been able to prevaricate for so long if it had been clearer that particular chemical carcinogens in cigarette tar mutate $p 53$ and other genes, and if the long latency (decades) and less than odds-on risk (about 1 in 10) of lung cancer in moderately heavy and persistent smokers had a persuasive molecular genetic explanation?

Traditional epidemiological approaches have not been able to deliver clear verdicts on causation for many of the other major cancer types - breast, prostate and colo-rectal carcinoma in particular. Similarly, success in the treatment of childhood leukaemia and a few other cancers has not yet been followed by major therapeutic inroads into the clinical control of adult epithelial carcinomas.

We and the general public are entitled to ask, why not? Is it not due in some measure to the fact that, until quite recently, we have pursued our clinical and epidemiological businesses in ignorance of the underlying biological complexity? But then, as Kinlen might reply, a 'laboratory scientist' would say that, wouldn't he?

\section{F. Greaves}

Leukaemia Research Fund Centre, Institute of Cancer Research, Chester Beatty Laboratories, 237 Fulham Road, London SW3 6JB, UK

1. Kinlen, L. Nature 405, 122-123 (2000).

2. Rose, S. Lifelines (Alan Lane/Penguin, London, 1997).

\section{Returners not welcome at Spanish universities}

Sir - Nature has published several articles regarding some of the obstacles that the Spanish scientific community faces in matters of appointments and research funding policies (Nature 396, 709 \& 712 (1998); 400, 203 (1999); 405, 723 (2000)).

We would like to draw attention to the case of many researchers who, having completed doctoral or postdoctoral training abroad, return to Spain with the financial support of very selective programmes sponsored by the EU, the state or the regional governments. The number of these "reincorporation contracts" is very small, and they are awarded after meticulous selection on the basis of scientific achievement. However, the selected candidates have to face discrimination in several areas in order to continue their academic careers.

As a group of current and former reincorporated researchers at the Universitat Autònoma de Barcelona (UAB), we believe our experiences are typical of the difficulties faced by people in our position.

Despite long negotiations with the university rectoral team, we still do not enjoy full academic status, our teaching and scientific activities at the UAB notwithstanding. We do not belong to the university elected body, where academic and administrative personnel as well as students are represented. Consequently, we do not have democratic rights. This situation is common to many Spanish universities.

Most importantly, the UAB officials have designed a lecturing policy document — now being implemented — that involves the creation of assistant professor positions for which only current UAB assistant lecturers are eligible. This allows our own $\mathrm{PhD}$ students to apply for these posts, while neither UAB researchers like us nor those from outside the UAB are eligible even if they are more qualified.
Our university was recently named as the top-scoring institution in a pioneering study, sponsored by the Ministry of Education and Culture, on the quality of Spanish universities in terms of educational development, organization, teaching resources, women's participation, doctorates and student success (Nature 402,$848 ; 1999$ ). Yet we are still subject to blatant endogamic practices, a barrier to the further development of high-quality research and teaching in the university.

\section{Pau Ferrer}

Department of Chemical Engineering, Universitat Autònoma de Barcelona, 08193-Bellaterra, Spain Other signatories to this letter:

Anna Gavarró, Josep M. Palet, Jordi Surrallès, Lluïsa M. Mir-Martínez, Jordi Ortiz, Alexandra Uscatescu, Lydia Giménez-Llort, Teresa Férriz-Roure, Begonya Saez-Tajafuerce UAB, Bellaterra, Spain

Josep Quer University of Amsterdam, Amsterdam, The Netherlands Maria A. Escobar ESERP SA, Barcelona, Spain Sandra Montón-Subías Universitat Pompeu Fabra, Barcelona, Spain Carles X. Simó Universität Bielefeld, Bielefeld, Germany Ramon Herrero Universitat Politècnica de Catalunya, Barcelona, Spain

\section{No evidence to link polio vaccine with HIV ...}

Sir - We would like to add two clarifications to your editorial and News story about the Royal Society meeting on the origin of human immunodeficiency virus (HIV) and the hypothesis that oral polio vaccine may have been contaminated ${ }^{1,2}$.

First, contrary to your statement, and as presented at the meeting, only two batches of vaccine were used in the mass vaccinations conducted in the Congo before 1959, the date of the first confirmed HIV infection in a human. No concrete or credible evidence exists that polio vaccine was produced locally in the Congo, and neither of the large lots produced in Philadelphia have been found to contain simian immunodeficiency virus (SIV) or HIV by the very sensitive polymerase chain reaction test conducted by independent laboratories ${ }^{3}$.

Second, you tax people in some other fields, particularly those working on xenotransplantation, with complacency about cross-species contamination. In the case of polio, we adapted attenuated vaccine strains to human diploid strains as soon as they became available, precisely because of concern regarding extraneous agents ${ }^{4}$. Stanley A. Plotkin ${ }^{\star}$, Hilary Koprowski $\dagger$ ${ }^{\star}$ Emeritus Professor, University of Pennsylvania, Doylestown, Pennsylvania 18901, USA †Thomas Jefferson University, Room M85, Jefferson Alumni Hall, Philadelphia, Pennsylvania 19107, USA

1. Nature 407, 115 (2000).

2. Dickson, D. Nature 407, 117 (2000).

3. Plotkin, S. A. Phil. Trans. R. Soc. Lond. (in the press).

4. Hayflick, L., Plotkin, S. A., Norton, T. W. \& Koprowski, H. Am. J. Hyg. 75, 240-258 (1962). 